\title{
Seventh-Line Therapy
}

National Cancer Institute

\section{Source}

National Cancer Institute. Seventh-Line Therapy. NCI Thesaurus. Code C133528.

Treatment that is given when the first six treatments don't work, or stop working. 